\title{
The predictive value of early intraocular pressure and bleb morphology in mitomycin-C augmented trabeculectomy
}

Hamed Esfandiari, M.D. ${ }^{1}$; Mohammad Pakravan, M.D. ${ }^{2}$; Nils A. Loewen, M.D, Ph.D. ${ }^{3}$; Mehdi Yaseri, Ph.D. ${ }^{4}$

${ }^{1}$ Ophthalmic Research Center, Shahid Beheshti University of Medical Sciences, Tehran, Iran

${ }^{2}$ Ophthalmic Epidemiology Research Center, Shahid Beheshti University of Medical Sciences, Tehran, Iran

${ }^{3}$ Department of Ophthalmology, School of Medicine, University of Pittsburgh, Pittsburgh, Pennsylvania, United States

${ }^{4}$ Department of Epidemiology and Biostatistics, School of Public Health, Tehran University of Medical Sciences, Tehran, Iran

Correspondence: Nils A. Loewen, loewen.nils@gmail.com

Running title: Predicting trabeculectomy outcomes

Keywords: Trabeculectomy; bleb morphology; grading scale 


\section{Abstract}

Purpose: To determine the predictive value of postoperative bleb morphologic features and intraocular pressure (IOP) on the success rate of trabeculectomy.

Methods: In this prospective interventional case series, we analyzed 80 consecutive open angle glaucoma patients who underwent mitomycin-augmented trabeculectomy. The IOP and bleb morphology was assessed before surgery and on day $1,7,14$, and month $1,3,6$, and 12 . The bleb morphology was scored according to the Indiana bleb appearance grading scale (IBAGS). Success was defined as IOP of $\leq 15 \mathrm{mmHg}$ with or without medications at 12 months. We tested for IOP and bleb morphological differences between groups and applied a multivariable regression analysis. The area under the receiver operating characteristic curve (AUC) was determined.

Results: The mean age of the study participants was $62.3 \pm 13.1$ years with equal gender distribution $(P=0.911)$. Patients matching the success definition of an IOP of $\leq 15 \mathrm{mmHg}$ at 12 months did not have an IOP that was statistically different from individuals with an unsuccessful outcome on day 1, 7 and 30 , respectively $(7.4 \pm 2.5$ vs $6.0 \pm 2.4 \mathrm{mmHg}(P=0.193), 7.8 \pm 2.5$ vs $7.1 \pm 2.1 \mathrm{mmHg}(P=0.639), 8.4 \pm 2.4$ vs $9.3 \pm 4.6 \mathrm{mmHg}(P=0.238))$. The AUC of IOP at day 1 , day 7 and 30 for a successful outcome was 0.355 , 0.452, and 0.80 , respectively. The AUC for bleb morphology parameters of bleb height, extension, and vascularization on day 14 were $0.368,0.408$, and 0.549 , respectively. Values for day 30 were 0.428 , 0.563 , and 0.654 . The IOP change from day 1 to day 30 was a good predictor of success (AUC=0.838, $95 \% \mathrm{Cl}: 0.704$ to 0.971$)$. A change in IOP less than or equal to $3 \mathrm{mmHg}$ was predictive of success at 12 months with a sensitivity of $82.5 \%$ (95\% Cl: 68 to $91 \%)$ and a specificity of $87.5 \%$ (95\% Cl: 53 to $98 \%$ ).

Conclusion: The postoperative IOP on day 30 had a fair to good accuracy while the bleb features failed to predict a successful outcome. An IOP increase by as little as $3 \mathrm{mmHg}$ during the first 30 days was a good predictor of failure. 


\section{Introduction}

The number of trabeculectomies has sharply declined in the last decades in most developed countries (Ramulu et al., 2007; Arora et al., 2015) for several reasons: more surgeons are now trained in microincisional glaucoma surgeries (Fallano et al., 2017; Dang et al., 2017) which can be performed sooner due to a superior risk profile (Kaplowitz et al., 2016); laser trabeculoplasty devices have become more affordable and are used as the first line of treatment (Rachmiel et al., 2006; Fraser \& Wormald, 2008); finally prostaglandin analogues are now available as generic, less expensive eye medications further reducing the number of trabeculectomies (Fraser \& Wormald, 2008). However, in economies categorized as developing by the International Monetary Fund (International Monetary Fund. Research Dept., 2016) and countries not in the upper quartile of the Human Development Index (UNDP, 2016), trabeculectomies remain the leading surgeries for moderate and severe glaucomas (Thomas, Sekhar \& Kumar, 2004; Anand et al., 2007). Although trabeculectomies have a considerable complication rate (Gedde et al., 2012), they remain a common primary procedure for advanced glaucoma because they lower intraocular pressure (IOP) effectively and are not as expensive as epibulbar glaucoma drainage devices (Kaplan et al., 2015) which involve a comparable surgical effort and risk profile.

Careful patient selection and postoperative management are key to making trabeculectomies successful. Recognized risk factors are, among others, younger age, a higher baseline IOP, and inflammation (AGIS, 1998; Landers et al., 2012). While careful preoperative planning, intraoperative use of antifibrotics, and the surgical technique impact the outcome, the postoperative period plays an equally important role (Marquardt, Lieb \& Grehn, 2004; Kirwan et al., 2013) including adjustment of the frequency of postoperative visits, adjustment of steroid frequency, release or lasering of scleral flap sutures, bleb massage, and bleb needling. Yet, even with the most personalized postoperative care, the individual wound healing and tissue remodeling make predicting a successful outcome difficult. Several recent studies have tried to capture the specific wound healing by correlating the early postoperative IOP or the bleb morphology with long-term outcomes and found that a low early postoperative IOP produces favorable long-term outcomes (Alwitry et al., 2007; Rong et al., 2013, 2014; Okimoto et al., 2014). In contrast, bleb grading systems are more complex, less objective but hold promise to describe data that is otherwise difficult to quantify; they have not been widely adopted (Cantor et al., 2003; Wells et al., 2006).

The purpose of our study was to validate in our patient population the accuracy of the early postoperative IOP and bleb morphology (Indiana Bleb Appearance Grading Scale (IBAGS)) as a test to 
predict a failure of trabeculectomy at 12 months. In contrast to prior studies, we also examined the role of an IOP increase during the first 30 postoperative days in predicting such failure.

\section{Methods}

\section{Study design}

Eighty eyes of 80 consecutive patients diagnosed with primary open angle glaucoma were included in this prospective observational study. In patients who had trabeculectomies in both eyes, the eye was chosen using a random number generator (Haahr). The study was performed at the glaucoma clinic of the Labbafinejad Medical Center from September 2013 to March 2015. The study was approved by the ethics committee at the Ophthalmic Research Center and followed the tenets of the Declaration of Helsinki. Informed written consent was obtained from each participant. Inclusion criteria were equal or above 30 years of age and progressive primary open angle glaucoma with a glaucomatous optic neuropathy and corresponding visual field defect that could not be controlled medically. Exclusion criteria consisted of prior ocular surgery, manipulation of the conjunctiva, a necessity for combining trabeculectomy with cataract extraction, ocular or systemic comorbidities that could affect the procedure and study outcomes such as immunodeficiency, connective tissue disease, and uncontrolled diabetes. At baseline, all patients underwent a comprehensive ophthalmic examination including determination of best-corrected visual acuity (BCVA), slit lamp examination, Goldmann applanation tonometry, gonioscopy, and fundus examination.

\section{Surgical technique and postoperative management}

All the surgeries were performed by two surgeons in equal numbers (HE and MP) as described in the following. After administration of intravenous sedation, a peribulbar block was placed using 2 milliliters (ml) of 2\% lidocaine (Lignidic 2\%, Caspian Tamin Pharmaceutical Co., Rasht, Iran). Following lid speculum insertion and cul de sacs irrigation with povidone-iodine and normal saline solution, a 7-0 silk traction suture was placed through the superior peripheral cornea. A superior peritomy was fashioned over 1-1/2 clock hours, and Tenon's capsule was dissected with Westcott scissors. A $3.0 \times 4.0 \mathrm{~mm}$ trapezoidal half-thickness scleral flap was fashioned using a crescent knife followed by lamellar dissection of the flap $1 \mathrm{~mm}$ into the clear cornea. After creating the scleral flap, small pieces of $0.02 \%$ 
MMC (Mitomycin C, Kyowa, Kogyo Company, Tokyo, Japan) soaked cellulose sponges were placed under the Tenon and conjunctiva over the scleral flap for 3 minutes. After removing the sponges and vigorously irrigating the area with $50 \mathrm{ml}$ of balanced salt solution (BSS), the anterior chamber was entered with a small keratome, and a block of clear cornea was removed with a $1 \mathrm{~mm}$ Kelly punch followed by a peripheral iridectomy using Vannas scissors. The scleral flap was then secured using two 10-0 nylon releasable sutures. The anterior chamber was formed by injection of BSS a paracentesis, and the filtration was titrated by adjusting the tension of the scleral flap sutures. The conjunctiva was closed using 10-0 nylon wing sutures. Cefazolin 50 mg (Cefazolin 500, Exir Pharmaceutical Co, Tehran, Iran) and betamethasone 2 mg (Betazone, Caspian Tamin Pharmaceutical CO., Rasht, Iran) were injected subconjunctivally into the inferior fornix, and the eye was patched.

The postoperative regimen consisted of chloramphenicol $0.5 \%$ eye drops (Sina Darou Lab. Co., Tehran, Iran) 4 times a day for 1 week and betamethasone 0.1\% eye drops (Sina Darou Lab. Co., Tehran, Iran) 6 times a day, which was tapered over 8 to 12 weeks depending on the degree of inflammation. The releasable sutures were removed as needed after 72 hours depending on bleb appearance to achieve IOPs near $10 \mathrm{mmHg}$. Needling was done during the postoperative period for impending failure from a contracting bleb. Thirty minutes after injecting $0.1 \mathrm{ml}$ of $0.02 \%$ mitomycin C into the bleb-adjacent subtenon space a 27 gauge needle was used to reform the bleb and dissect adhesions at the slit lamp.

We saw our patients on a weekly basis for one month and then monthly for 12 months. At each postoperative visit, BCVA, IOP, bleb morphology, glaucoma medications, and complications were noted. A slit lamp photograph of the blebs was obtained at each visit (Haag-Streit BX 900 slit lamp, Haag-Streit Diagnostics, Köniz, Switzerland). Two glaucoma surgeons, masked to surgeon and patient, graded the bleb images on the Indiana Bleb Appearance Grading Scale (IBAGS). The IBAGS variables included the bleb height (HO-H3), extent (EO-E3), vascularity (VO-V4), and leakage (SO-S2) (Cantor et al., 2003). A trabeculectomy was considered successful if IOP was equal or less than $15 \mathrm{mmHg}$ with or without antiglaucoma medications (Alwitry et al., 2007). Failure was defined as IOP $>15 \mathrm{mmHg}$ with glaucoma medications or less than $5 \mathrm{~mm} \mathrm{Hg}$ at the final visit.

\section{Statistics}

Data was described as mean \pm standard deviation (SD), median, range, 95\% confidence interval $(95 \% \mathrm{Cl})$ and frequency (percentage). To evaluate for difference between the two groups we used the $t$-test, 
Mann-Whitney, Chi-square and Fisher exact test. A change in visual acuity before and after surgery was evaluated by the Wilcoxon signed-rank test. The predictive power of bleb variables was measured with the area under the receiver operator characteristic curve (AUC). In order to find the relative risk (RR, Supplemental Table) of failure by bleb morphology and IOP at the 1-month visit, a Cox regression with defined constant time was used. Youden's J statistic was used to capture the performance of variables (bleb morphology, IOP) as a diagnostic test. All statistical analyses were done with the SPSS software package (IBM Corp. Released 2016. IBM SPSS Statistic for Windows, Version 24.0, Armonk, NY).

\section{Results}

A total of 80 patients were enrolled in this study. This sample size and ratio of success and failure provided an above $90 \%$ power to detect an AUC difference of 0.5 (Hanley \& McNeil, 1982). Forty-four eyes would have provided a power of $80 \%$ to detect an IOP change of $3 \mathrm{mmHg}$ while 80 eyes allowed for a $97 \%$ power. Mean age of the study participants was $62.3 \pm 13.1$ years, and $51.3 \%$ of the patients were male $(P=0.911)$. The patients' demographic data are presented in Table 1 . The procedure was considered successful in 64 patients (80\%) at 12 months follow-up. There were no significant differences between the success and failure groups in terms of age, the number of preoperative antiglaucoma medications (Table 1), and intraocular pressure (Table 2). The best corrected visual acuity did not change significantly $(0.47 \pm 0.47 \log M A R$ at baseline, $0.48 \pm 0.48$ postoperatively, $\mathrm{P}=0.492)$. Mean IOP decreased significantly from $21.8 \pm 5 \mathrm{mmHg}$ at baseline to $10.6 \pm 3.8 \mathrm{mmHg}$ at 12 months $(p<0.001)$, and 25 patients needed glaucoma medications to have their IOP within the target range. There were no intraoperative complications. The most common postoperative complication was a shallow anterior chamber, followed by bleb leakage and hyphema as summarized in Table 3. The difference between success and failure groups in a leak, repeat suture, hyphema and shallow anterior chamber were insignificant ( $\mathrm{P}=0.09,0.99,0.59$, and 0.18 , respectively). Bleb needling was more frequently performed in the group that failed $(P<0.001)$. One eye experienced hypotony maculopathy. Patients with a final IOP of $\leq 15 \mathrm{mmHg}$ had a mean day 1 IOP of $7.4 \pm 2.5 \mathrm{mmHg}$ compared with $6 \pm 2.4$ $\mathrm{mmHg}$ in those with an IOP above $15 \mathrm{mmHg}$ at final follow-up $(P=0.193)$. Respective values for day 7 were $7.8 \pm 2.5$ and $7.1 \pm 2.1 \mathrm{mmHg}(P=0.639)$, and for day 30 values were $8.4 \pm 2.4$ and $9.3 \pm 4.6 \mathrm{mmHg}$ $(P=0.238)$. The AUC for IOP at day 1 , day 7 and 30 as a predictor of success was $0.355,0.452$, and 0.80 respectively. The bleb morphology parameters according to the IBAGS are detailed in Table 4. The AUC for bleb morphology parameters of bleb height, extension, and vascularization on day 14 were 0.368 , 
0.408 and 0.549 , respectively. The AUC values for day 30 were $0.428,0.563$, and 0.654 . Based on the AUCs, there was no single bleb variable at month 1 to predict success at month 12 .

Interestingly, the AUC of the IOP change from day 1 to day 30 was a good predictor of success ( $A \cup C=0.838,95 \% \mathrm{Cl}: 0.704$ to 0.971, Supplementary Table). Based on Youden's J index, the change in IOP less than or equal to $3 \mathrm{mmHg}$ could predict the success in month 12 with the sensitivity of $82.5 \%$ (95\% Cl: 68 to $91 \%)$ and specificity of $87.5 \%(95 \% \mathrm{Cl}: 53$ to $98 \%)$.

\section{Discussion}

Trabeculectomy remains a common surgery to lower IOP in glaucoma patients and has a long history. In 1958, Grant first described a guarded filtering procedure in enucleated eyes with subsequent facility measurements which he termed trabeculectomy (Grant, 1958). Sugar followed by performing the first trabeculectomy in patients in 1961 (Saul Sugar, 1961) while Cairns popularized the term and technique by providing detailed drawings and figures (Cairns, 1968). The procedure was eventually made more effective by adding mitomycin-C as an antifibrotic (Chen et al., 1990) and somewhat titratable by using sutures that can be lasered or manually released (Aykan et al., 2007; Liang et al., 2014). The variable success rate of this procedure can be improved by careful patient selection, surgical technique (Edmunds et al., 2001), and postoperative management (Landers et al., 2012). Identifying patients at risk is critical because a timely intervention can improve the outcomes of trabeculectomy (Marquardt, Lieb \& Grehn, 2004); preoperative factors such as high baseline IOP, number of glaucoma medications, young age, aphakia or pseudophakia and prior surgery with conjunctival scarring are known risk factors for failure (Edmunds et al., 2001).

Several recent studies found that a low early postoperative IOP produces favorable long-term outcomes (Asamoto, Yablonski \& Matsushita, 1996; Alwitry et al., 2007; Rong et al., 2013, 2014; Okimoto et al., 2014) but also causes more frequent and more severe complications that include a shallow anterior chamber, choroidal effusion, hypotony maculopathy, and vision loss (Hara et al., 1998). In contrast to these studies, we found only a weak relationship between IOP at day 1,7 , and 30 and long term success, similar to Polikoff et al. (Polikoff et al., 2005) who also reported that early post-trabeculectomy IOP is a poor predictor of success at one year follow-up. The accuracy of a test depends on how well it separates groups under study into those with and without the issue in question. Accuracy is measured by the area under the ROC curve and commonly classified into $.90-1=$ excellent, $.80-.90=$ good, $.70-.80=$ fair, $.60-.70=$ poor and $.50-.60=$ fail (Hanley \& McNeil, 1982). In our 
study, the AUC for IOP was the highest on day 30 with 0.8, making it a fair to good predictor (Hanley \& McNeil, 1982). Early post-trabeculectomy IOP is affected by various factors that include reduced aqueous production, inflammation, the amount of TGF-beta and other growth factors (Group \& Others, 2007), and breakdown of the blood-aqueous barrier, over filtration, and choroidal detachment. In our study, the IOP appears to summarize these and other factors reasonably well to as a single variable that can be used as a predictor.

Different from other studies, we also examined the change in IOP during the first 30 days and found that it served as a good predictor of success that performs better than the IOP itself. The cutoff for an at-risk IOP elevation was only $3 \mathrm{mmHg}$. Our study was not designed to discover causality. It is likely that this finding identifies patients at risk of failure who experienced an IOP increase despite an intensified treatment. It could also indicate that these were patients who received a suboptimal postoperative management. An increased IOP will increase the stretch of the bleb wall and incite a reactive fibrosis. Stretch is a well-established activator of fibroblast proliferation and fibrosis (Chiquet et al., 2003; Wang et al., 2007). This may lead to a cycle of auto-enhancing IOP increase with further increase of stretch and fibrosis that again elevates pressure as the bleb wall becomes thicker and the bleb contracts. In this model, IOP drives the morphological changes of the bleb. This order matches our AUC findings better (the AUC was better for IOP change than for bleb morphology) than a primary morphological change that is followed by increased IOP. Our observation is supportive of the practice to inject or needle with postoperative 5-fluorouracil or mitomycin C to reduce the fibrosis (Broadway et al., 2004; Anand \& Khan, 2009).

Like IOP, a bleb's morphology is a reflection of a patient's specific wound healing that is directly observable but more difficult to quantify. The development of bleb grading scales was an attempt to approach this problem systematically (Cantor et al., 2003; Wells et al., 2006). While grading systems can be useful teaching tools of bleb features, its inherently subjective nature and categorical data weaken the predictive power. Accordingly, we found only low AUC values for bleb morphology that ranged from 0.368 to 0.549 on day 14 and would be interpreted as a test failure. The day 30 features would be interpreted only slightly better, as poor. Of the variables bleb height, extension and vascularization, vascularization had the highest accuracy. These findings match Picht et al. (Picht \& Grehn, 1998) who concluded that an early vascularization indicates a poor prognosis with higher IOP at 12 months and support the use of anti-VEGF agents (Kahook, 2010; Nilforushan et al., 2012). 
In conclusion, we found that the IOP changes during the first month, rather than the IOP at each visit, was a good predictor of failure. The bleb morphological features did not predict failure except for bleb vascularity which performed poorly to fairly. These finding highlights how important it is to carefully observe for IOP and bleb vascularity changes and to intervene swiftly if necessary.

\section{Acknowledgment}

We would like to sincerely thank the Ophthalmic Research Center of Shahid Beheshti University of Medical Science for their support.

\section{Funding}

This work was supported by The Eye and Ear Foundation of Pittsburgh

\section{Competing interest}

NAL has received honoraria from Neomedix Inc. for wet labs and lectures in the last year. 


\section{References}

AGIS. 1998. The Advanced Glaucoma Intervention Study (AGIS): 4. Comparison of treatment outcomes within race. Seven-year results. Ophthalmology 105:1146-1164.

Alwitry A., Moodie J., Rotchford A., Abedin A., Patel V., King AJ. 2007. Predictive value of early IOP in mitomycin-C augmented trabeculectomy. Journal of glaucoma 16:616-621.

Anand N., Khan A. 2009. Long-term outcomes of needle revision of trabeculectomy blebs with mitomycin C and 5-fluorouracil: a comparative safety and efficacy report. Journal of glaucoma 18:513-520.

Anand A., Negi S., Khokhar S., Kumar H., Gupta SK., Murthy GVS., Sharma TK. 2007. Role of early trabeculectomy in primary open-angle glaucoma in the developing world. Eye 21:40-45.

Arora KS., Robin AL., Corcoran KJ., Corcoran SL., Ramulu PY. 2015. Use of Various Glaucoma Surgeries and Procedures in Medicare Beneficiaries from 1994 to 2012. Ophthalmology. DOI: 10.1016/j.ophtha.2015.04.015.

Asamoto A., Yablonski ME., Matsushita M. 1996. Predicting long-term results of trabeculectomy from early postoperative intraocular pressure levels. Ophthalmic surgery and lasers 27:355-360.

Aykan U., Bilge AH., Akin T., Certel I., Bayer A. 2007. Laser suture lysis or releasable sutures after trabeculectomy. Journal of glaucoma 16:240-245.

Broadway DC., Bloom PA., Bunce C., Thiagarajan M., Khaw PT. 2004. Needle revision of failing and failed trabeculectomy blebs with adjunctive 5-fluorouracil: survival analysis. Ophthalmology 111:665-673.

Cairns JE. 1968. Trabeculectomy: Preliminary Report of a New Method. American journal of ophthalmology 66:673-679.

Cantor LB., Mantravadi A., WuDunn D., Swamynathan K., Cortes A. 2003. Morphologic classification of filtering blebs after glaucoma filtration surgery: the Indiana Bleb Appearance Grading Scale. Journal of glaucoma 12:266-271.

Chen CW., Huang HT., Bair JS., Lee CC. 1990. Trabeculectomy with simultaneous topical application of mitomycin-C in refractory glaucoma. Journal of ocular pharmacology 6:175-182.

Chiquet M., Renedo AS., Huber F., Flück M. 2003. How do fibroblasts translate mechanical signals into changes in extracellular matrix production? Matrix biology: journal of the International Society for Matrix Biology 22:73-80.

Dang Y., Waxman S., Wang C., Parikh HA., Bussel II., Loewen RT., Xia X., Lathrop KL., Bilonick R., Loewen NA. 2017. Rapid learning curve assessment in an ex vivo training system for microincisional glaucoma surgery. PeerJ Preprints. DOI: 10.7287/peerj.preprints.2745v1.

Edmunds B., Thompson JR., Salmon JF., Wormald RP. 2001. The National Survey of Trabeculectomy. II. Variations in operative technique and outcome. Eye 15:441-448.

Fallano K., Bussel I., Kagemann L., Lathrop KL., Loewen N. 2017. Training strategies and outcomes of $a b$ 
interno trabeculectomy with the trabectome. F1000Research 6. DOI: 10.12688/f1000research.10236.1.

Fraser SG., Wormald RPL. 2008. Hospital Episode Statistics and changing trends in glaucoma surgery. Eye 22:3-7.

Gedde SJ., Herndon LW., Brandt JD., Budenz DL., Feuer WJ., Schiffman JC., Tube Versus Trabeculectomy Study Group. 2012. Postoperative complications in the Tube Versus Trabeculectomy (TVT) study during five years of follow-up. In: Am J Ophthalmol. Bascom Palmer Eye Institute, Miller School of Medicine, University of Miami, Florida, USA. sgedde@med.miami.edu: 2012 Elsevier Inc, 804-814.e1.

Grant WM. 1958. Further studies on facility of flow through the trabecular meshwork. A.M.A. archives of ophthalmology 60:523-533.

Group C-152 TS., Others. 2007. Factors affecting the outcome of trabeculectomy: An analysis based on combined data from two phase III studies of an antibody to transforming growth factor $\beta 2$, CAT-152. Ophthalmology 114:1831-1838.

Haahr M.RANDOM.ORG - True Random Number Service. Available at https://www.random.org/ (accessed February 6, 2017).

Hanley JA., McNeil BJ. 1982. The meaning and use of the area under a receiver operating characteristic (ROC) curve. Radiology 143:29-36.

Hara T., Araie M., Shirato S., Yamamoto S. 1998. Conditions for balance between lower normal pressure control and hypotony in mitomycin trabeculectomy. Graefe's archive for clinical and experimental ophthalmology = Albrecht von Graefes Archiv fur klinische und experimentelle Ophthalmologie 236:420-425.

International Monetary Fund. Research Dept. 2016. World Economic Outlook, October 2016: Subdued Demand: Symptoms and Remedies. International Monetary Fund.

Kahook MY. 2010. Bleb morphology and vascularity after trabeculectomy with intravitreal ranibizumab: a pilot study. American journal of ophthalmology 150:399-403.e1.

Kaplan RI., De Moraes CG., Cioffi GA., Al-Aswad LA., Blumberg DM. 2015. Comparative Cost-effectiveness of the Baerveldt Implant, Trabeculectomy With Mitomycin, and Medical Treatment. JAMA ophthalmology 133:560-567.

Kaplowitz K., Bussel II., Honkanen R., Schuman JS., Loewen NA. 2016. Review and meta-analysis of ab-interno trabeculectomy outcomes. The British journal of ophthalmology 100:594-600.

Kirwan JF., Lockwood AJ., Shah P., Macleod A., Broadway DC., King AJ., McNaught Al., Agrawal P., Trabeculectomy Outcomes Group Audit Study Group. 2013. Trabeculectomy in the 21st century: a multicenter analysis. Ophthalmology 120:2532-2539.

Landers J., Martin K., Sarkies N., Bourne R., Watson P. 2012. A twenty-year follow-up study of trabeculectomy: risk factors and outcomes. Ophthalmology 119:694-702.

Liang YB., Feng MY., Meng HL., Fan SJ., Wang X., Xie LL., Yi P., Tang X., Wang NL., Thomas R. 2014. Early efficacy and complications of releasable sutures for trabeculectomy in primary angle-closure glaucoma: a 
randomized clinical trial. Journal of glaucoma 23:136-141.

Marquardt D., Lieb WE., Grehn F. 2004. Intensified postoperative care versus conventional follow-up: a retrospective long-term analysis of 177 trabeculectomies. Graefe's archive for clinical and experimental ophthalmology = Albrecht von Graefes Archiv fur klinische und experimentelle Ophthalmologie 242:106-113.

Nilforushan N., Yadgari M., Kish SK., Nassiri N. 2012. Subconjunctival bevacizumab versus mitomycin C adjunctive to trabeculectomy. American journal of ophthalmology 153:352-357.e1.

Okimoto S., Kiuchi Y., Akita T., Tanaka J. 2014. Using the early postoperative intraocular pressure to predict pressure control after a trabeculectomy. Journal of glaucoma 23:410-414.

Picht G., Grehn F. 1998. Classification of filtering blebs in trabeculectomy: biomicroscopy and functionality. Current opinion in ophthalmology 9:2-8.

Polikoff LA., Taglienti A., Chanis RA., Ramos-Esteban JC., Donas N., Tsong J., Gagliuso DJ., Danias J., Serle JB. 2005. Is intraocular pressure in the early postoperative period predictive of antimetabolite-augmented filtration surgery success? Journal of glaucoma 14:497-503.

Rachmiel R., Trope GE., Chipman ML., Gouws P., Buys YM. 2006. Laser trabeculoplasty trends with the introduction of new medical treatments and selective laser trabeculoplasty. Journal of glaucoma 15:306-309.

Ramulu PY., Corcoran KJ., Corcoran SL., Robin AL. 2007. Utilization of various glaucoma surgeries and procedures in Medicare beneficiaries from 1995 to 2004. Ophthalmology 114:2265-2270.

Rong SS., Feng MY., Wang N., Meng H., Thomas R., Fan S., Wang R., Wang X., Tang X., Liang YB. 2013. Can early postoperative intraocular pressure predict success following mitomycin-C augmented trabeculectomy in primary angle-closure glaucoma. Eye 27:403-409.

Rong SS., Meng HL., Fan SJ., Wang NL., Liang YB., Huang Y., Wang R., He Y., Chang X., Cui HY., Zhang ZH., Li SZ., Liu LR., Thomas R. 2014. Can intraoperative intraocular pressure during primary trabeculectomy predict early postoperative pressure? Journal of glaucoma 23:653-657.

Saul Sugar H. 1961. Experimental Trabeculectomy in Glaucoma *. American journal of ophthalmology 51:623-627.

Thomas R., Sekhar GC., Kumar RS. 2004. Glaucoma management in developing countries: medical, laser, and surgical options for glaucoma management in countries with limited resources. Current opinion in ophthalmology 15:127-131.

UNDP. 2016. Human Development Report 2015.

Wang JH-C., Thampatty BP., Lin J-S., Im H-J. 2007. Mechanoregulation of gene expression in fibroblasts. Gene 391:1-15.

Wells AP., Ashraff NN., Hall RC., Purdie G. 2006. Comparison of two clinical Bleb grading systems. Ophthalmology 113:77-83. 


\section{Tables}

\section{Table 1}

Table 1: Baseline characteristics of participants.

\begin{tabular}{|c|c|c|c|c|c|}
\hline & & \multirow{2}{*}{ Total } & \multicolumn{2}{|l|}{ Success } & \multirow{2}{*}{$P$} \\
\hline & & & No $(n=16)$ & Yes $(n=64)$ & \\
\hline age & Mean $\pm S D$ & $62.3 \pm 13.1$ & $63.2 \pm 16.3$ & $62 \pm 12.3$ & $0.430 \dagger$ \\
\hline \multirow[t]{2}{*}{ sex } & male & 41 (51.3\%) & $8(50.0 \%)$ & 33 (51.6\%) & $0.911 *$ \\
\hline & female & 39 (48.8\%) & $8(50.0 \%)$ & 31 (48.4\%) & \\
\hline \multirow[t]{2}{*}{ Baseline BCVA } & Mean \pm SD & $0.47 \pm 0.47$ & $0.37 \pm 0.37$ & $0.49 \pm 0.49$ & $0.334 \ddagger$ \\
\hline & $\begin{array}{l}\text { Median } \\
\text { (range) }\end{array}$ & 0.3 (0 to 2.8 ) & $\begin{array}{l}0.24 \text { (0 to } \\
1.1)\end{array}$ & 0.3 (0 to 2.8$)$ & \\
\hline \multirow[t]{2}{*}{ Baseline IOP } & Mean $\pm S D$ & $21.8 \pm 5.0$ & $20.4 \pm 3.3$ & $22.1 \pm 5.3$ & $0.171 \ddagger$ \\
\hline & $\begin{array}{l}\text { Median } \\
\text { (range) }\end{array}$ & 21 (11 to 32 ) & 20 (16 to 28$)$ & $\begin{array}{l}22.5 \text { (11 to } \\
32)\end{array}$ & \\
\hline \multirow[t]{2}{*}{ Baseline meds } & Mean \pm SD & $1.2 \pm 1.6$ & $1.4 \pm 1.9$ & $1.2 \pm 1.6$ & $0.785 \ddagger$ \\
\hline & $\begin{array}{l}\text { Median } \\
\text { (range) }\end{array}$ & 0 (0 to 4$)$ & 0 (0 to 4$)$ & 0 (0 to 4$)$ & \\
\hline
\end{tabular}

BCVA: Best Corrected Visual Acuity. IOP: Intraocular Pressure. † Based on t-test. $\ddagger$ Based on Mann-Whitney test. * Based on Chi-Square test. 


\section{Table 2}

Table 2: Intraocular pressure in each pre and postoperative visit.

\begin{tabular}{|c|c|c|c|c|c|c|c|c|}
\hline \multirow[b]{2}{*}{ Time } & \multicolumn{2}{|l|}{ No success } & \multicolumn{2}{|l|}{ Success } & \multirow{2}{*}{$P \ddagger$} & \multirow{2}{*}{$A \cup C$} & \multicolumn{2}{|l|}{$95 \% \mathrm{Cl}$} \\
\hline & Mean $\pm S D$ & $\begin{array}{l}\text { Median } \\
\text { (range) }\end{array}$ & Mean $\pm S D$ & $\begin{array}{l}\text { Median } \\
\text { (range) }\end{array}$ & & & Lower & Upper \\
\hline Baseline & $21.2 \pm 3.4$ & $\begin{array}{l}20(17 \\
\text { to } 28)\end{array}$ & $21.9 \pm 5.2$ & $\begin{array}{l}21 \text { (11 to } \\
32)\end{array}$ & 0.654 & 0.473 & 0.297 & 0.65 \\
\hline Day 1 & $6 \pm 2.4$ & $\begin{array}{l}6.5 \text { (3 } \\
\text { to 9) }\end{array}$ & $7.4 \pm 2.5$ & $\begin{array}{l}8(2 \text { to } \\
13)\end{array}$ & 0.193 & 0.355 & 0.147 & 0.562 \\
\hline Week 2 & $7.1 \pm 2.1$ & $\begin{array}{l}7 \text { ( } 3 \text { to } \\
10)\end{array}$ & $7.8 \pm 2.5$ & $\begin{array}{l}8 \text { ( } 4 \text { to } \\
18)\end{array}$ & 0.639 & 0.452 & 0.239 & 0.664 \\
\hline Month 1 & $9.3 \pm 4.6$ & $\begin{array}{l}10(2 \\
\text { to } 16)\end{array}$ & $8.4 \pm 2.4$ & $\begin{array}{l}9 \text { ( } 3 \text { to } \\
19)\end{array}$ & 0.238 & 0.8 & 0.581 & 1 \\
\hline Month 3 & $12.6 \pm 6.8$ & $\begin{array}{l}14(2 \\
\text { to } 21)\end{array}$ & $9.5 \pm 2.5$ & $\begin{array}{l}10 \text { (5 to } \\
17)\end{array}$ & 0.143 & 0.85 & 0.635 & 1 \\
\hline Month 6 & $14.1 \pm 7.7$ & $\begin{array}{l}17(4 \\
\text { to } 23)\end{array}$ & $9.9 \pm 2$ & $\begin{array}{l}10 \text { (5 to } \\
15)\end{array}$ & 0.133 & 0.875 & 0.646 & 1 \\
\hline $\begin{array}{l}\text { Month } \\
12\end{array}$ & $13.7 \pm 7.3$ & $\begin{array}{l}17(4 \\
\text { to } 23)\end{array}$ & $10.1 \pm 1.7$ & $\begin{array}{l}10 \text { (6 to } \\
15)\end{array}$ & 0.143 & 0.875 & 0.646 & 1 \\
\hline
\end{tabular}

‡ Based on Mann-Whitney test. 


\section{Table 3}

Table 3: List of postoperative complications.

\begin{tabular}{|c|c|c|c|c|}
\hline & \multirow{2}{*}{ Total } & \multicolumn{2}{|l|}{ Success } & \multirow{2}{*}{$P$} \\
\hline & & No & Yes & \\
\hline Bleb leakage & $6(7.5 \%)$ & $3(18.8 \%)$ & $3(4.7 \%)$ & $0.091 * *$ \\
\hline Bleb resuturing & $1(1.3 \%)$ & $0(0.0 \%)$ & $1(1.6 \%)$ & $>0.99 * *$ \\
\hline Hyphema & $6(7.5 \%)$ & $2(12.5 \%)$ & $4(6.3 \%)$ & $0.594 * *$ \\
\hline $\begin{array}{l}\text { Shallow anterior } \\
\text { chamber }\end{array}$ & $8(10.0 \%)$ & $3(18.8 \%)$ & $5(7.8 \%)$ & $0.194 * *$ \\
\hline Bleb needling & $\begin{array}{l}10 \\
(12.5 \%)\end{array}$ & $8(50.0 \%)$ & $2(3.1 \%)$ & $<0.001 * *$ \\
\hline
\end{tabular}




\section{Table 4}

Table 4: Bleb morphologic characteristics at each postoperative visit.

\begin{tabular}{|c|c|c|c|c|c|c|c|c|c|}
\hline \multirow[b]{2}{*}{ Parameter } & \multirow[b]{2}{*}{ Time } & \multicolumn{2}{|l|}{ No success } & \multicolumn{2}{|l|}{ Success } & \multirow[b]{2}{*}{$P \ddagger$} & \multirow[b]{2}{*}{$A \cup C$} & \multicolumn{2}{|l|}{$95 \% \mathrm{Cl}$} \\
\hline & & Mean士SD & $\begin{array}{l}\text { Median } \\
\text { (range) }\end{array}$ & Mean $\pm S D$ & $\begin{array}{l}\text { Median } \\
\text { (range) }\end{array}$ & & & Lower & Upper \\
\hline \multirow[t]{5}{*}{ Bleb H } & Week 2 & $2.45 \pm 0.69$ & 3 (1 to 3$)$ & $2.17 \pm 0.54$ & 2 (1 to 3$)$ & 0.098 & 0.368 & 0.172 & 0.564 \\
\hline & Month 1 & $2.27 \pm 0.65$ & 2 (1 to 3 ) & $2.12 \pm 0.53$ & 2 (1 to 3$)$ & 0.35 & 0.428 & 0.233 & 0.624 \\
\hline & Month 3 & $1.64 \pm 0.67$ & 2 (1 to 3 ) & $1.96 \pm 0.4$ & 2 (1 to 3$)$ & 0.024 & 0.652 & 0.444 & 0.859 \\
\hline & Month 6 & $1.36 \pm 0.5$ & 1 (1 to 2 ) & $1.78 \pm 0.54$ & 2 (1 to 3$)$ & 0.017 & 0.691 & 0.523 & 0.859 \\
\hline & Month 12 & $1.36 \pm 0.5$ & 1 (1 to 2 ) & $1.74 \pm 0.56$ & 2 (1 to 3$)$ & 0.038 & 0.669 & 0.5 & 0.838 \\
\hline \multirow[t]{5}{*}{ Bleb E } & Week 2 & $2.55 \pm 0.52$ & 3 (2 to 3 ) & $2.36 \pm 0.48$ & 2 (2 to 3$)$ & 0.25 & 0.408 & 0.224 & 0.592 \\
\hline & Month 1 & $2.18 \pm 0.4$ & 2 (2 to 3 ) & $2.3 \pm 0.49$ & 2 (1 to 3$)$ & 0.41 & 0.563 & 0.391 & 0.734 \\
\hline & Month 3 & $1.73 \pm 0.65$ & 2 (1 to 3 ) & $2.12 \pm 0.4$ & 2 (1 to 3 ) & 0.012 & 0.669 & 0.47 & 0.869 \\
\hline & Month 6 & $1.55 \pm 0.52$ & 2 (1 to 2 ) & $2.09 \pm 0.37$ & 2 (1 to 3 ) & $\begin{array}{l}<0.00 \\
1\end{array}$ & 0.744 & 0.568 & 0.92 \\
\hline & Month 12 & $1.82 \pm 0.75$ & 2 (0 to 2 ) & $1.95 \pm 0.53$ & $1(0$ to 1$)$ & 0.002 & 0.749 & 0.57 & 0.928 \\
\hline \multirow[t]{5}{*}{ Bleb V } & Week 2 & $2.18 \pm 0.6$ & 2 (1 to 3 ) & $2.3 \pm 0.49$ & 2 (1 to 3$)$ & 0.53 & 0.549 & 0.357 & 0.74 \\
\hline & Month 1 & $1.82 \pm 0.6$ & 2 (1 to 3 ) & $2.19 \pm 0.52$ & 2 (1 to 3$)$ & 0.045 & 0.654 & 0.474 & 0.834 \\
\hline & Month 3 & $1.64 \pm 0.67$ & 2 (0 to 2$)$ & $1.86 \pm 0.49$ & 2 (1 to 3$)$ & 0.368 & 0.565 & 0.38 & 0.751 \\
\hline & Month 6 & $1.55 \pm 0.69$ & 2 (0 to 2 ) & $1.54 \pm 0.53$ & $2(0$ to 2$)$ & 0.76 & 0.475 & 0.282 & 0.668 \\
\hline & Month 12 & $1.36 \pm 0.67$ & 1 (0 to 2$)$ & $1.46 \pm 0.53$ & 1 (0 to 2$)$ & 0.702 & 0.532 & 0.338 & 0.725 \\
\hline
\end{tabular}

H: height. E: extension. V: vascularization. $\ddagger$ Based on Mann-Whitney test. 